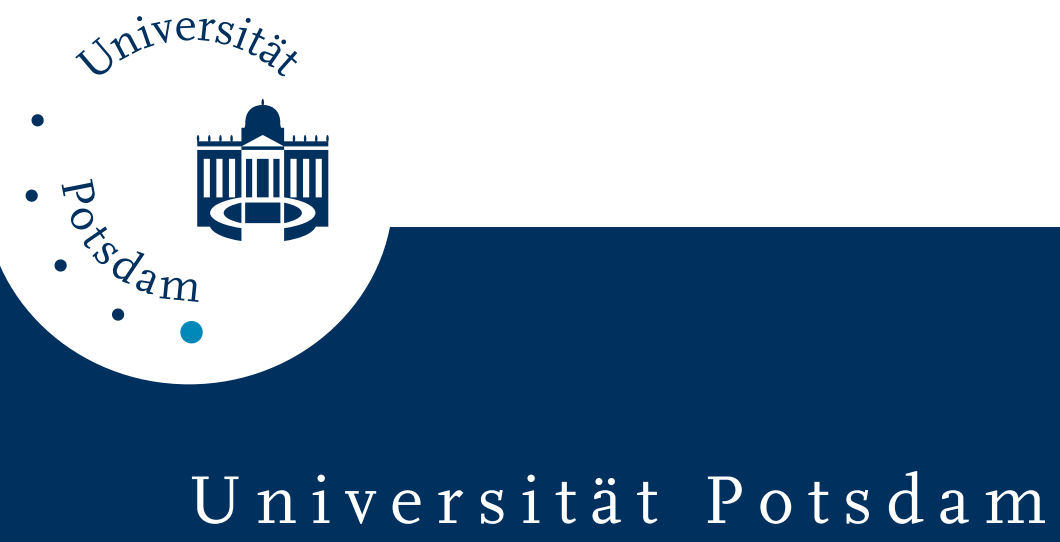

Anton, P.; Laschewsky, André

\title{
Solubilization by polysoaps
}

first published in:

Colloid \& Polymer Science, 272 (1994), 9, S. 1118-1128, ISSN 0303-402X;

DOI 10.1007/BF00652381

Postprint published at the Institutional Repository of Potsdam University:

In: Postprints der Universität Potsdam

Mathematisch-Naturwissenschaftliche Reihe ; 83

http://opus.kobv.de/ubp/volltexte/2008/1732/

http://nbn-resolving.de/urn:nbn:de:kobv:517-opus-17327

Postprints der Universität Potsdam

Mathematisch-Naturwissenschaftliche Reihe ; 83 


\title{
Solubilization by polysoaps
}

\author{
P. Anton ${ }^{1}$ ) and A. Laschewsky*) \\ Dépt. de Chimie, Université Catholique de Louvain, Louvain-la-Neuve, Belgium \\ $\left.{ }^{1}\right)$ Institut für Organische Chemie, Universität Mainz, Mainz, Germany
}

\begin{abstract}
The aqueous solubilization power of several series of micellar homopolymers and copolymers ("polysoaps") is investigated. Using five insoluble or poorly water-soluble dyes, comparisons of the capacities are made with respect to the influence of structural variables such as the polymer backbone, the polymer geometry, the comonomer content, and the charge of the hydrophilic group. Some guidelines for polysoap structures suited for efficient solubilization are established. Noteworthy is that the solubilization capacities of the polysoaps are neither linked to the ability to reduce the surface tension of water, nor to the polarity of the solubilization sites deduced from spectroscopic probes.
\end{abstract}

Key words: Micellar polymers - polysoaps - solubilization

\section{Introduction}

Polysoaps [1-3] represent a particularly interesting class of water-soluble polymers, by virtue of their self-organization in homogeneous aqueous solution due to hydrophobic interactions. They can be visualized as a large number of individual surfactant structures linked by a polymer backbone as, for example, obtained by polymerization of surfactant monomers. As polysoaps show primarily intramolecular aggregation, important differences to the aggregational behaviour of low molecular weight surfactants exist, such as the missing equivalent to the critical micelle concentration (CMC).

Solubilization [4] capability is considered a key property of low molecular weight surfactants. Although solubilization is simultaneously influenced by the surfactant and the solubilizate chosen, thus rendering investigations complicated, at least useful rules for solubilization have been established in the past, despite the lack of a unified picture [5-7].
In the case of micellar polymers the situation is obscure. Only few data are available, and the majority of the studies focus on the solubilization sites [8-16] rather than on the solubilization capacities [17-25]. Hence, we have investigated the solubilization capacity of polysoaps for various sparingly water-soluble dyes, using mostly zwitterionic polysoaps [3]. The choice of zwitterionic polymers avoids the problems linked to polyelectrolytes, as well as the ones resulting from very voluminuous hydrophilic groups as present in most non-ionic polysoaps.

\section{Experimental part}

\section{Materials}

$\mathrm{N}, \mathrm{N}$-dimethyl-N-dodecyl-3-ammoniopropanesulfonate 21 was a commercial product (Fluka, BioChemika) and used without purification. The synthesis of polymers $P-1-P-7$ and $P-12-P-20$ has been described previously, as well as the synthesis

*) to whom correspondance should be addressed 
of the monomers for copolymers $\mathrm{Co}-11$, polymer $P-15$ and of surfactant $22[14,26-29]$. The monomers of $P-8-P-10$ were synthesized in analogy to $P-7$ [28] and to similar compounds in the literature [30]; the polymers and copolymers were prepared by radical polymerization using AIBN as described before [14,26-29]. The copolymer compositions are based on elemental analysis in the case of $\mathrm{Co}-13-\mathrm{Co}-17$ [14], and on UV-spectroscopy in the case of $\mathrm{Co}-11$. Standard techniques failed to give reliable average molecular weights of the polymers; from the missing signals of AIBN residues in the FT-IR-spectra of the polymers, a minimal degree of polymerization of 20 is concluded $[28,29]$. Polymeric samples prepared by using a naphthalene labeled azo-initiator [26] under otherwise identical conditions had average number molecular weights of ca. $10^{5}$ according to end-group analysis. However, such labeled polymers were not used for the measurements to exclude artefacts of the functional end groups. Water was purified by a Milli-Q water purification system (resistance $18 \mathrm{MOhm}$ ).

\section{Methods}

Surface tensions were measured with a semiautomatic tensiometer TE $1 \mathrm{C} / 2$ (Lauda) at $25^{\circ} \mathrm{C}$, using platinum rings $(1 \mathrm{~cm}$ and $2 \mathrm{~cm}$ diameter $)$ and glass vessels $(5 \mathrm{~cm}$ diameter). Values were corrected according to Harkins and Jordan [32]. In the concentration range studied, polymer solutions required equilibration times of between 1d and $3 \mathrm{~d}$.

For solubilization studies, aqueous soap solutions of concentration $4 \mathrm{~g} / \mathrm{L}$ were prepared. $2 \mathrm{mg}$ solid dye per $1 \mathrm{ml}$ of solution were added, and the suspensions were shaken at $22^{\circ} \mathrm{C}$ with $200 \mathrm{~min}^{-1}$ for 4 weeks. After allowing most of the undissolved dye to settle down during 1 week, the solutions are filtered and centrifuged for $30 \mathrm{~min}$ with $1.2 \times 10^{4} \mathrm{~min}^{-1}$. The resulting clear solutions are placed into quartz glass cuvettes with thickness of $1 \mathrm{~cm}$. In the case of cyanine dyes $S 4$ and $S 5$, the solutions had to be diluted with water by a factor of 10 . As in the case of dye $S 5$ solubilized by low molecular weight surfactant 21 the dilution by water-induced reprecipitation of solubilized dye, dilution of these samples was performed using methanol. UV-spectra were recorded with a Lambda $5 \mathrm{UV} /$ Vis-spectrometer
(Perkin Elmer) $2 \mathrm{~nm}$ resolution. The given values are averages of several samples. The results of individual samples varied by less than $20 \%$.

\section{Polysoaps investigated}

Beyond the classical structural variables of the surfactant side chains, such as the nature of the head group and the length and branching of the alkyl chain, additional variables result from the combination of polymer and surfactant structures in polysoaps [3]. For example, the polymer structure can be varied with respect to the nature of the polymer backbone, thus defining its flexibility and modifying its hydrophilicity (and thus the HLB). Most important, the backbone defines the length of the repeat unit, too, which controls the density of the surfactant side chains ("main chain spacer" effect) $[14,29]$. Or, the polymer structure can be varied with respect to its geometry, producing polysoaps with the backbone attached at different positions of the surfactant side chains [3,33-35] (compare Fig. 8). As these variables distinguish polysoaps from low molecular weight surfactants, we have focused our major interest on them.

The polysoaps chosen have been investigated previously with respect to solubility in aqueous systems, surface activity, and solubilization of pyrene $[14,26,28,29,33]$. As the polymer geometry has been found to be of major importance for the basic properties such as solubility, the polymers studied are classified accordingly in Figs. 1-3. The various polysoaps differ with respect to the polarity of the polymer backbone and the nature of the hydrophilic group.

Figure 1 comprises the polysoaps of the "tail end" type, with the backbone attached at the end of the hydrophobic tail. Polymers $P-1-P-5$ are polyzwitterions, i.e., the macromolecules bear no net charge, whereas polymers $P-6-\mathrm{Co}-11$ are formed from single or double positively charged surfactants. Figure 2 presents the zwitterionic polysoaps of the "mid tail" type, with the backbone attached at the hydrophobic tail, but close to the head group. Figure 3 lists zwitterionic and cationic polysoaps of the "head" type, with the backbone attached at the hydrophilic head group.

As vinylic polysoaps of the "mid tail" and the "head" type require the use of "main chain spacers" to achieve water-solubility [3], such spacers 


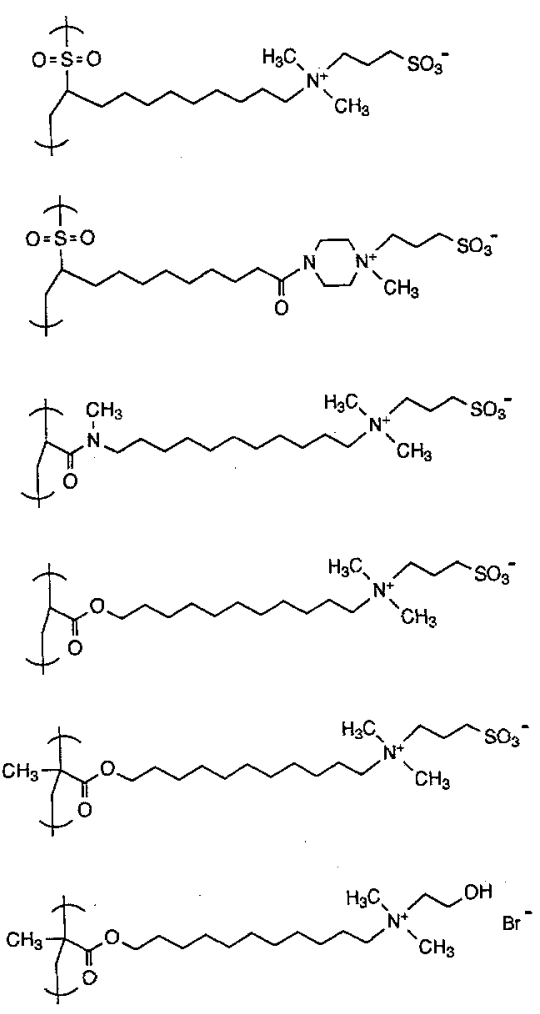

P-1
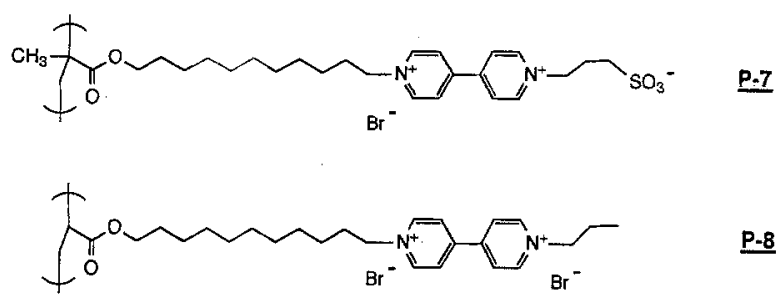

$\underline{p-2}$

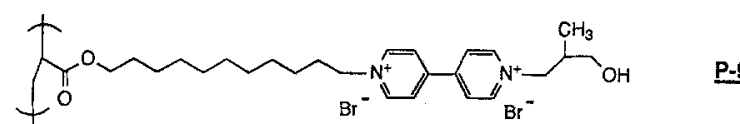

P-3

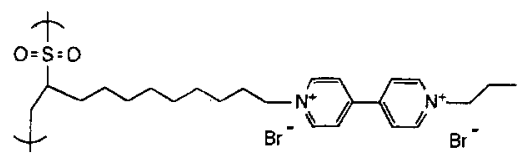

$\underline{\text { P-5 }}$

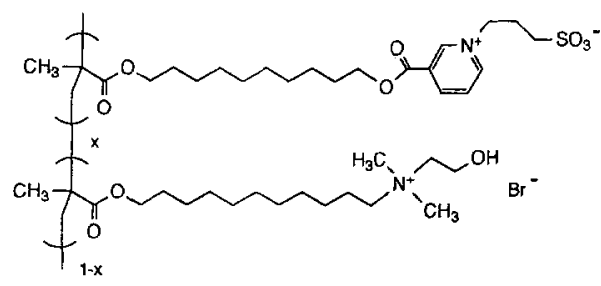

Co-11b: $x=0.33$

Co-11c: $x=0.16$

Co-11d: $x=0.11$

Fig. 1. Polysoaps of tail-end type geometry investigated

were incorporated via the copolymerization with polar comonomers. Only in the case of polydiene $P-12$ is the $(1,4)$ repeat unit sufficiently long to enable water-solubility of the homopolymer [29]. As the homopolymer of the zwitterionic derivative of nicotinic acid used in copolymer series $\mathrm{Co}$ 11 is insoluble in water, presumably due to strong attractive interactions between the pyridinioammoniosulfonate moieties [27], copolymers with the cationic monomer from $P-6$ were employed. Still, only copolymers with high contents of cationic comonomer such as $\mathrm{Co}-11 \mathrm{C}$ and $\mathrm{Co}$ $11 d$ are soluble in water, but not $\mathrm{Co}-11 \mathrm{~b}$. Concerning surface activity, all the zwitterionic polymers [3] and the viologen derivatives [28] are moderately surface active, with no indication of a CMC, as illustrated in Fig. 4. The semilogarithmic plots of the surface tension versus polysoap concentration are surprisingly similar, even for copolymer series $\mathrm{Co}-13-\mathrm{Co}-17$ with different polar comonomer contents [14]. In contrast, the reference homopolymers $P-18-P-20$ and the cationic polysoap $P-6$ are only very weakly surface active. The cationic copolymer $\mathrm{Co}-17$ behaves intermediately. As the cationic comonomer used is strongly hydrophilic, thus changing the hydrophilic-hydrophobic balance notably, surface activity decreases with increasing comonomer content [14].

Using the ratio of the fluorescence emission bands I and III ("py-scale" [36,37]), solubilization studies of the polysoaps with pyrene enabled studies of the environment of the solubilizate, i.e., studies on the solubilization site. All polymers are able to provide a rather hydrophobic environment for pyrene, even at high dilution. However, the I/III ratios generally indicated solubilization sites which are less polar than the ones provided by micelles of analogous low molecular weight surfactants above the CMC $[26,33]$. Within the polysoaps studied, the most polar sites according to the pyrene emission 
<smiles>CCCCCCCCCC(C)(C)CC(C=CC(CC)C(=O)NCC[N+](C)(C)CCCO)CC</smiles>
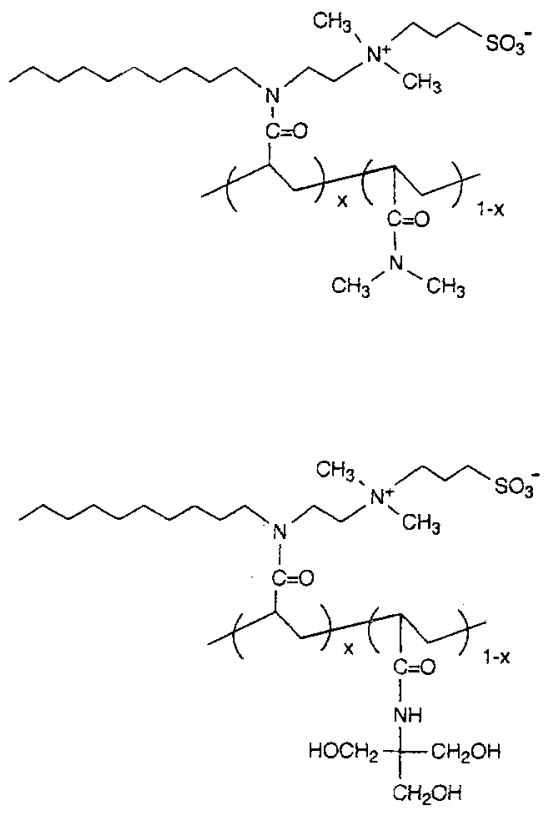

Co-14b: $x=0.25$

Co-14c: $x=0.18$

Co-14d: $x=0.09$ spectra were found for polymers of the tail end type, the least polar ones for polymers of the head type [14].

\section{Solubilizates chosen}

Five solubilizates with different characteristics were chosen which all bear a strong chromophore to enable UV/Vis spectroscopic studies (Fig. 5). Dyes $S 1-S 3$ are not charged, $S 4$ is cationic dye, and $S 5$ is a zwitterionic one. Within the uncharged solubilizates, cumarin $S 1$ is the most polar and most water-soluble one. Although the bulky azo-dye $S 2$ bears a number of polar groups, it is the least water-soluble of the solubilizates studied. Nitrophenolether $S 3$ represents a weak amphiphile. The charged dyes $S 4$ and $S 5$ can be classified as weak surfactants, with single and double chains, respectively, the latter being very poorly water-soluble.

Some spectral characteristics of the dyes in water, in isopropanol, and in the cases of $S 1-S 3$ in hexane are listed in Table 1. Dyes $S 2-S 5$ show a marked solvatochromism. In the case of the virtually water-insoluble azodye $S 2$, the strong bathochromic shift observed in pure water is difficult to understand on a molecular base; presumably it results from dye aggregation. Similar considerations apply for the strong hypsochromic shift observed for $S 5$ in pure water.

\section{Results and discussion}

\section{General solubilization behaviour}

Under the experimental conditions, solubilizate uptake is rather slow. One week was not sufficient for all samples, but after 2 weeks apparently maximal solubilization was reached. To ensure full equilibration, experiments were conducted over 4 weeks, before removing the undissolved material from the polysoap solutions. All filtered solutions were clear and more or less colored. 


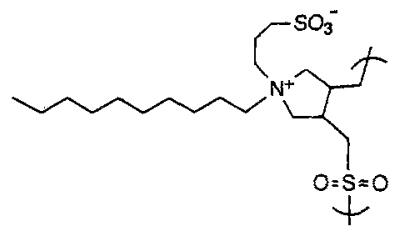

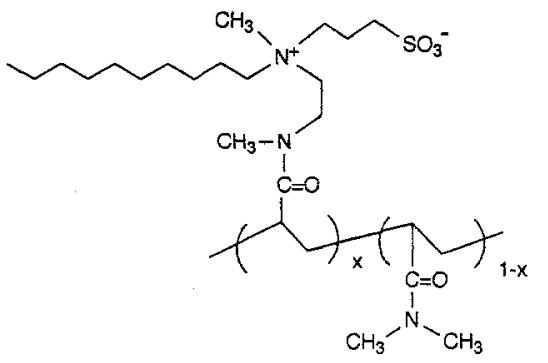

Co-16c: $x=0.16$

Co-16d: $x=0.09$

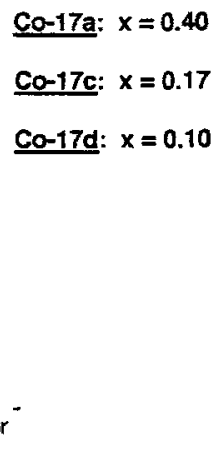

Fig. 3. Polysoaps of head-type geometry investigated

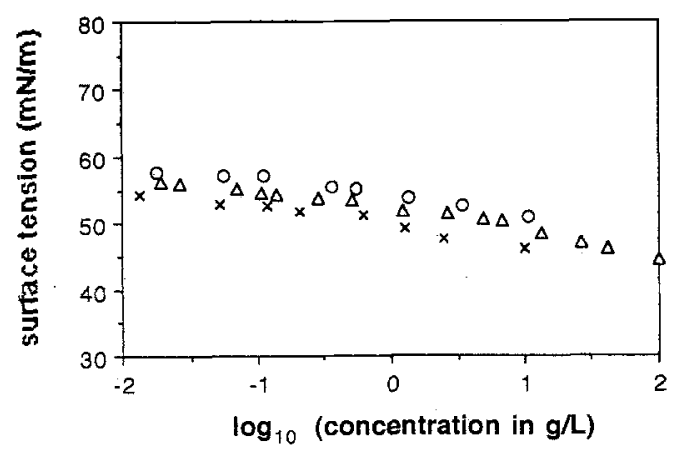

Fig. 4. Surface activity of some zwitterionic tail-end type polysoaps: $\bigcirc=P-3, \times=P-4, \triangle=P-5$

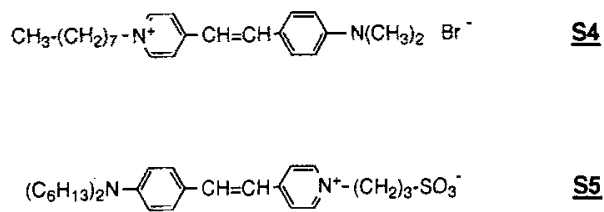

Fig. 5. Hydrophobic dyes used for solubilization studies

Table 1. UV/Vis-spectroscopic data of the dyes used for solubilization experiments

\begin{tabular}{|c|c|c|c|c|}
\hline Solubilizate & Water & $\begin{array}{c}\lambda_{\max }(\mathrm{nm}) \\
\text { i-Propanol }\end{array}$ & Hexane & $\begin{array}{l}\varepsilon(\mathrm{L} / \mathrm{cm} \cdot \mathrm{mol}) \\
\text { i-Propanol }\end{array}$ \\
\hline $\mathrm{S} 1$ & 381 & 372 & 371 & $2.9 \times 10^{4}$ \\
\hline $\mathrm{S} 2$ & $\left.460^{a}\right)$ & 411 & 406 & $3.2 \times 10^{4}$ \\
\hline S3 & 317 & 306 & 274 & $3.0 \times 10^{4}$ \\
\hline S4 & 452 & 487 & $\left.--^{b}\right)$ & $6.0 \times 10^{4}$ \\
\hline S5 & $\left.378^{a}\right)$ & 495 & $-6)$ & $6.1 \times 10^{4}$ \\
\hline
\end{tabular}

Solutions containing the non-hydrophobized watersoluble polymers $P 18-P 20$ and the low molecular weight surfactants $21(\mathrm{CMC}:=1.2 \mathrm{~g} / \mathrm{L})$ and $22(\mathrm{CMC}:=1.0 \mathrm{~g} / \mathrm{L})$ served as references (Fig. 6). Attempts to directly use the monomers of the polysoaps for the comparison of monomeric soap/polysoap failed, because of spontaneous polymerization occurring in the lengthy course of the experiments. On account of the structural similarity, surfactant 22 seems the better reference for the polysoaps than is 21 , but the use of both surfactants guarantees a realistic reference in any case.

Although solubilization kinetics were not quantified in detail, maximal solubilizate uptake was reached faster by the low molecular weight surfactants than by the polymers. The amounts of dyes solubilized by the different polysoap solutions 
<smiles>CN(C)C1CCCO1</smiles>

$\underline{\text { P-18 }}$

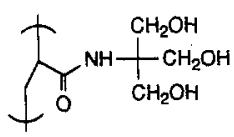

$\underline{\text { P-19 }}$

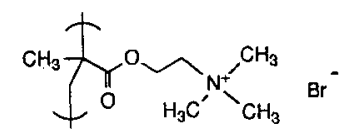

$\underline{\mathbf{P}-20}$
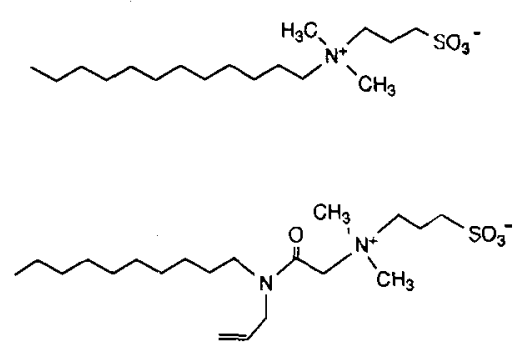

$\underline{21}$

$\underline{22}$
Fig. 6. Reference polymers and low molecular weight surfactants used were calculated from the adsorbance maximum using the extinction coefficient determined in isopropanol (Table 1). The values obtained and the wavelength of the adsorption maximum are for dyes $S 1-S 3$ listed in Table 2. Table 3 contains the results of the ionic dyes $S 4$ and $S 5$, whose solubilizations were only studied for polysoaps of the tail-end type.

As often found in solubilization studies, results are complex and difficult to interpret by a simple, unified analysis. Nevertheless, the large number of combinations of polysoaps and solubilizates enables some general conclusions.

First of all, all polysoaps are capable of solubilization, although important differences are found in the absolute capacities depending on the polysoap/solubilizate pair chosen. In contrast, the solubilizing capacities of the reference homopolymers $P 18-P 20$ without surfactant structures are marginal. The polysoaps apparently are capable of solubilization at any concentration, whereas the reference surfactants 21 and 22 require concentrations above their $\mathrm{CMC}$. In agreement, polysoap solutions containing solubilized dye are stable against extreme dilution, whereas the solubilized dyes precipitate upon dilution in the low molecular weight surfactant solutions. Often, the solubilization capacities of the polysoaps are inferior to the ones of the two reference surfactants studied, but there exist numerous examples where the capacities of the low molecular weight surfactants are matched, or even surpassed (Tables 2 and 3).

\section{Solvatochromic effects}

Looking at solvatochromic effects, the absorbence maxima of the solubilized dyes are located between the values in water and in isopropanol, thus pointing to rather polar solubilization sites. The reference surfactants 21 and 22 exhibit absorbence maxima, indicating a slightly less polar environment than in most polysoap systems studied. The slight solvatochromic shifts found for dyes $S 1$ and $S 3$ between different polysoaps are not useful for quantitative evaluation, keeping the spectral resolution of $2 \mathrm{~nm}$ in mind. This is surprisingly true as well for $S 4$ and $S 5$, considering the widespread use of cyanine dyes as solvatochromic probes $[38,39]$. But, in fact, the spectral differences are marginal, except for electrostatic effects: The cationic dye $S 4$ shows a spectral shift of ca. $10 \mathrm{~nm}$ between zwitterionic $(P-l$ and $P-5)$ and cationic polysoaps $(P-6-\mathrm{Co}-11)$; the zwitterionic dye $S 5$ seems to exhibit a similar general trend distinguishing between cationic and zwitterionic polysoaps, but the effect is much smaller. The lack of marked solvatochromic differences may indicate that similar aggregates, i.e., "polymeric micelles," are formed by all polysoaps studied [38], but this conclusion contrasts with the results of the pyrene studies [14]. The reasons 
Table 2. Solubilization of nonionic dyes $S 1-S 3$ by various polysoaps at $22^{\circ} \mathrm{C}$ (soap concentration: $=4 \mathrm{~g} / \mathrm{L}$ ).

\begin{tabular}{|c|c|c|c|c|c|c|}
\hline \multirow{3}{*}{$\begin{array}{l}\text { Solubilizing agent } \\
\text { Reference }\end{array}$} & \multirow{3}{*}{$\frac{S 1}{\left(10^{-3} \mathrm{~g} / \mathrm{L}\right)}$} & \multirow{2}{*}{\multicolumn{3}{|c|}{$S 2 \quad$}} & \multirow{3}{*}{$\frac{S 3}{\left(10^{-3} \mathrm{~g} / \mathrm{L}\right)}$} & \multirow[b]{3}{*}{$\begin{array}{l}\lambda_{\max } \\
\text { (nm) }\end{array}$} \\
\hline & & & & & & \\
\hline & & $\begin{array}{l}\lambda_{\max } \\
(\mathrm{nm})\end{array}$ & $\left(10^{-3} \mathrm{~g} / \mathrm{L}\right)$ & $\begin{array}{l}\lambda_{\max } \\
(\mathrm{nm})\end{array}$ & & \\
\hline water & 24 & 381 & $<0.2$ & 460 & 4 & 317 \\
\hline P-18 & 24 & 381 & 0.2 & 425 & 4 & 317 \\
\hline P-19 & 32 & 381 & 0.2 & 425 & 7 & 318 \\
\hline P-20 & 29 & 381 & 0.3 & 425 & 6 & 315 \\
\hline 21 & 190 & 376 & 52 & 418 & 220 & 313 \\
\hline 22 & 140 & 375 & 42 & 414 & 130 & 310 \\
\hline $\begin{array}{l}\text { Polysoap } \\
\text { tail-end geometry }\end{array}$ & $\left(10^{-3} \mathrm{~g} / \mathrm{L}\right)$ & $\lambda_{\max }$ & $\left(10^{-3} \mathrm{~g} / \mathrm{L}\right)$ & $\lambda_{\max }$ & $\left(10^{-3} \mathrm{~g} / \mathrm{L}\right)$ & $\lambda_{\max }$ \\
\hline P-1 & 50 & 382 & 1.5 & 420 & 9 & 318 \\
\hline P-2 & 39 & 381 & 1.6 & 421 & 9 & 316 \\
\hline$P-3$ & 69 & 382 & 5.9 & 421 & 16 & 316 \\
\hline P-4 & 180 & 379 & 17 & 422 & 68 & 318 \\
\hline P-5 & 170 & 378 & 21 & 423 & 83 & 317 \\
\hline P-6 & 260 & 378 & 23 & 425 & 86 & 317 \\
\hline P-7 & & & 13 & 419 & & \\
\hline P-8 & & & 13 & 418 & & \\
\hline P-9 & & & 13 & 419 & & \\
\hline P-10 & & & 1.6 & 420 & & \\
\hline $\mathrm{Co}-11 \mathrm{c}$ & & & 31 & 425 & & \\
\hline Co-11d & & & 24 & 425 & & \\
\hline $\begin{array}{l}\text { Polysoap } \\
\text { mid-tail geometry }\end{array}$ & $\left(10^{-3} \mathrm{~g} / \mathrm{L}\right)$ & $\lambda_{\max }$ & $\left(10^{-3} \mathrm{~g} / \mathrm{L}\right)$ & $\lambda_{\max }$ & $\left(10^{-3} \mathrm{~g} / \mathrm{L}\right)$ & $\lambda_{\max }$ \\
\hline $\mathrm{P}-12$ & 66 & 375 & 21 & 409 & 120 & 313 \\
\hline $\mathrm{Co}-13 \mathrm{a}$ & 85 & 375 & 18 & 414 & 110 & 313 \\
\hline $\mathrm{Co}-13 \mathrm{~b}$ & 97 & 375 & 15 & 415 & 84 & 314 \\
\hline $\mathrm{Co}-13 \mathrm{c}$ & 73 & 377 & 9.6 & 414 & 32 & 315 \\
\hline Co-13d & 58 & 379 & 7.3 & 414 & 22 & 315 \\
\hline $\mathrm{Co}-14 \mathrm{~b}$ & 84 & 378 & 10.2 & 416 & 64 & 318 \\
\hline $\mathrm{Co}-14 \mathrm{c}$ & 59 & 380 & 3.1 & 416 & 23 & 318 \\
\hline Co-14d & 36 & 380 & 2.4 & 416 & 12 & 318 \\
\hline $\begin{array}{l}\text { Polysoap } \\
\text { head geometry }\end{array}$ & $\left(10^{-3} \mathrm{~g} / \mathrm{L}\right)$ & $\lambda_{\max }$ & $\left(10^{-3} \mathrm{~g} / \mathrm{L}\right)$ & $\lambda_{\max }$ & $\left(10^{-3} \mathrm{~g} / \mathrm{L}\right)$ & $\lambda_{\max }$ \\
\hline$P-15$ & & & 4.9 & 415 & & \\
\hline $\mathrm{Co}-16 \mathrm{c}$ & 62 & 378 & 4.8 & 416 & 21 & 317 \\
\hline Co-16d & 47 & 380 & 2.7 & 416 & 13 & 317 \\
\hline Co-17a & 67 & 380 & 6.7 & 411 & 18 & 317 \\
\hline $\mathrm{Co}-17 \mathrm{c}$ & 29 & 381 & 2.6 & 410 & 9 & 317 \\
\hline $\mathrm{Co}-17 \mathrm{~d}$ & 25 & 381 & 2.4 & 411 & 8 & 317 \\
\hline
\end{tabular}

for this apparent inconsistency are not clear, but in fact, conclusions based on solvatochromism should be taken with great care considering recent studies on cyanine probes [39].

Only in the case of azodye $S 2$ are the solvatochromic effects more notable, though difficult to interpret. The absorbence maximum exhibits a slight bathochromic shift for the tail-end type polysoaps, compared to the mid-tail- and headtype ones. This implies a slightly less polar environment for mid-tail-type and head-type polysoaps, in agreement with some recent studies using pyrene as probe [14]. Apart from this general trend, there is no obvious correlation to the detailed molecular structure of the polysoaps and the solvatochromic shift observed. 
Table 3. Solubilization of ionic dyes $S 4$ and $S 5$ by various polysoaps at $22^{\circ} \mathrm{C}$ (soap concentration: $=4 \mathrm{~g} / \mathrm{L}$ ).

\begin{tabular}{lllll}
\hline $\begin{array}{l}\text { Solubilizing } \\
\text { agent }\end{array}$ & \multicolumn{5}{c}{$S 4$} & \multicolumn{3}{c}{ Solubilized dye } \\
Reference & $(\mathrm{g} / \mathrm{L})$ & $\begin{array}{l}\lambda_{\max } \\
(\mathrm{nm})\end{array}$ & $(\mathrm{g} / \mathrm{L})$ & $\begin{array}{l}\lambda_{\max } \\
(\mathrm{nm})\end{array}$ \\
& & & & \\
Water & 0.24 & 452 & 0.01 & 378 \\
21 & 0.42 & 450 & 0.12 & \\
Polysoap & $(\mathrm{g} / \mathrm{L})$ & $\lambda_{\max }$ & $(\mathrm{g} / \mathrm{L})$ & $\lambda_{\max }$ \\
& & $(\mathrm{nm})$ & & $(\mathrm{nm})$ \\
P-1 & 0.52 & 459 & 0.11 & 481 \\
P-5 & 0.41 & 457 & 0.21 & 483 \\
P-6 & 0.21 & 448 & 0.69 & 479 \\
P-7 & 0.31 & 449 & 0.66 & 477 \\
P-8 & 0.16 & 448 & 0.40 & 480 \\
P-9 & 0.15 & 444 & 0.54 & 477 \\
Co-11c & 0.26 & 448 & 0.69 & 477 \\
Co-11d & 0.25 & 448 & 0.74 & 477 \\
\hline
\end{tabular}

\section{Influence of the head groups}

The comparison of the zwitterionic and cationic polysoaps $P-1-C o-11 d$ of the tail-end type enables some conclusions on the role of the hydrophilic head group chosen. Here, it has to be distinguished between uncharged solubilizates such as $S I-S 3$ (Table 2) and charged ones such as $S 4$ and $S 5$ (Table 3).

In the case of the hydrophobic uncharged solubilizates $S 2$ and $S 3$, the very close analogs $P-5$ (zwitterionic) and $P-6$ (cationic) behave nearly the same. The same is true for the viologen analogs $P-7-P-9$, being single or double charged. Hence, the charge of the headgroup is not necessarily important. In contrast, structural modifications of the head group as between $P-6$ and $P-11 c$, which are both cationic, result in marked differences between the solubilization capacities. The same is true comparing the aliphatic ammonium derivatives $P-5$ and $P-6$ with the viologen analogs $P-7-P-9$.

These findings do not exclude that the charge of the headgroup can sometimes influence the capacity for uncharged solubilizates, as exemplified by cumarine $S 1$. Here, the cationic $P-6$ is nearly twice as efficient as the zwitterionic $P-5$. This might imply specific interactions between headgroup and solubilizate, although this is not indicated by a shift of the absorbence maximum (Table 2).
In the case of the charged solubilizates $S 4$ and $S 5$, major differences are found between zwitterionic and cationic polysoaps (Table 3). The cationic $S 4$ is much better solubilized by the zwitterionic and partially zwitterionic polysoaps $P-1, P-5$ or $P-7$. In fact, the cationic polysoaps, in particular the double charged viologens $P-8$ and $P-9$ do not improve, but even decrease the solubility of the dye in water. The opposite effect is found for the zwitterionic dye $S 5$. Here, the cationic polysoaps are superior to zwitterionic ones. Clearly, the solubilization of charged solubilizates is dominated by electrostatic effects.

\section{Effect of the main chain spacer (hydrophobe content)}

The copolymer series $\mathrm{Co}-13, \mathrm{Co}-14, \mathrm{Co}-16$, and Co-17 provides sets of polysoaps with analogous structure, but different hydrophobe content [14]. As all copolymers studied were capable of solubilization, the critical hydrophobe content [2] to enable intramolecular aggregation is below $10 \%$ for these copolymers, which compares well with other polysoaps of similar structure [2]. Table 2 shows that the solubilization capacities within these series increase with the amount of surfactant incorporated, with the exception of cumarin $S 1$ solubilized by $\mathrm{Co}-13 a$. Possibly, this copolymer with a high surfactant content and thus a short main chain spacer unit suffers from steric problems to accommodate the rather polar cumarin dye in the "surface layer" of the polymeric micelles. This explanation is supported by the even lower solubilization capacity found for the polydiene $P-12$ in case of $S 1$, which is the most densely packed polysoap of the mid-tail type investigated. In contrast for the other more hydrophobic dyes studied, polysoaps $P-12$ and $C O-13 a$ exhibit the maximal solubilization capacities. Unfortunately, clarifying comparisons are not possible with the series $\mathrm{Co}-14, \mathrm{Co}-16$ and $\mathrm{Co}-17$, i.e., with the other polymers of the mid-tail and head type, because of the long main chain spacers needed to achieve water-solubility $[14,29]$.

For the various copolymer series studied, the solubilization capacity appears to increase approximately linearly with the hydrophobe content as exemplified in Fig. 7, with the above-mentioned exception. As the amounts of solubilized dye increase linearly with the concentration of the 


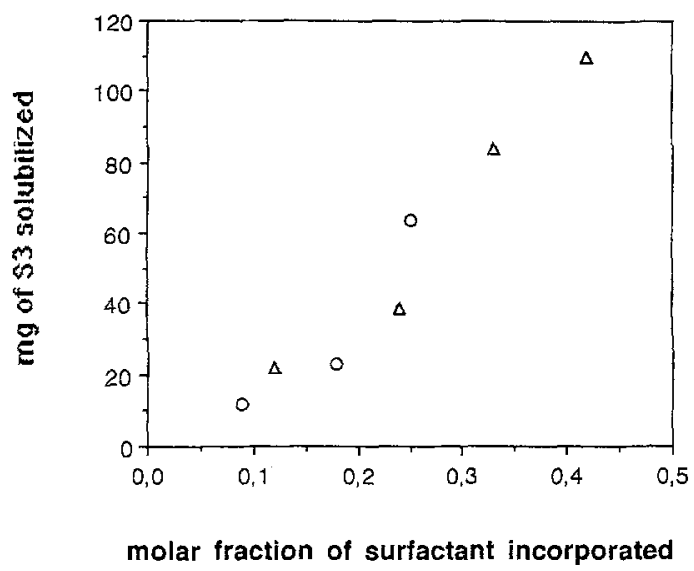

Fig. 7. Solubilization of nitrophenylether $S-3$ by polysoaps of copolymer series $\mathrm{Co}-13(\triangle)$ and $\mathrm{Co}-14(\mathrm{O})$, as function of surfactant monomer content $\left(22^{\circ} \mathrm{C}\right.$, soap concentration: $=4 \mathrm{~g} / \mathrm{L}$ ).

polysoaps (at least up to concentrations of $4 \mathrm{~g} / \mathrm{L}$ ), this suggests that generally the solubilization capacity per surfactant unit is constant, and the small, polar comonomers do not contribute, as already indicated by the marginal solubilizing effects of the respective homopolymers $P-18-$ $P$-20. Accordingly, the decreased performance of polysoaps with large main chain spacers is a dilutional rather than a structural effect. In agreement, the solubilization capacity per surfactant unit is very close for copolymer series $\mathrm{Co}-13$ and $\mathrm{Co}_{-14}$ (Fig. 7), which are based on the same surfactant monomer, but differ in the "spacer comonomer" used.

\section{Polarity of the polymer backbone}

Generally, polymerizable moieties and the resulting polymer backbones contain some polar elements. Hence, the polarity of the backbone is intermediate between the hydrophobic chain, and the hydrophilic head group. The effect of the backbone polarity on the solubilization capacity is well illustrated by the comparison of the analogous zwitterionic polymers $P-1-P-5$ of the tailend type. Clearly, the capacity for all dyes increases strongly with the hydrophobicity of the polymer backbone, i.e., sulfones $P-1, P-2$, acrylamide $P-3<$ acrylate $P-4<$ methacrylate $P-5$. In the case of the polysulfones $P-1$ and $P-2$ the reduced lengths of the hydrophobic chains

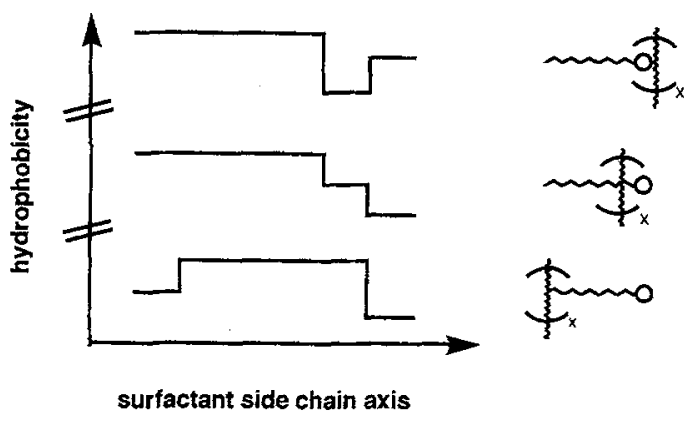

Fig. 8. Schematic polarity profile in polysoaps

presumably contribute as well to the low capacities. This effect of the backbone is attributed to the more advantageous polarity profile of tail-end polysoaps with unpolar backbones (Fig. 8).

The inverse prediction of this model, the preferential use of very hydrophilic backbones in case of head type polysoaps, is difficult to verify directly due to the limited range of chemical variations; rather hydrophilic backbones - such as polyacrylamide - are needed to achieve water-solubility, but the hydrophilicity of the charged headgroups cannot be matched by the backbone.

However, the model is corrobated indirectly, as within the "isomeric" polysoaps $P-3, P-12$ or Co-13 or Co-14 and Co-16 having the polar polyacrylamide backbone, the mid-tail ones $P-12$ and $C o-13 a / b$ and $C o-14 a$ show the best results. Even considering the capacity per hydrophobic chain, the mid-tail series $\mathrm{Co}-13$ performs better than the "isomeric" head type series Co-16 [3]. This may be attributed to the ideal polarity profile always present in mid-tail polysoaps which have the backbone attached close to the head group of the surfactant side chain (Fig. 8), which is most important when using polar backbones such as polyacrylamide.

We note that the hierarchy of solubilization capacity does not agree with the hierarchy of unpolar environment provided by the polysoaps, as determined by pyrene fluorescence [14], or as might be concluded from the solvatochromic trend shown by dye $S 2$.

\section{Polymer geometry}

The effect of the polymer geometry on the solubilization capacity is rather complex. As for 
a given polymer backbone the resulting polarity profile strongly influences the solubilization capacity, overall comparisons have to be based on "optimized" polysoaps of the various geometries, rather than on "isomeric" ones. Thus, within the polysoaps studied, the tail-end type is represented best by methacrylate $P-5$, the mid-tail type by acrylamide $P-12$ and the head type by acrylamide $\mathrm{Co}-16 \mathrm{c}$. The latter is obviously not the optimal structure (see discussion above), but is the best choice available.

By analyzing the data of Table 2, it becomes clear that "optimized" polysoaps exhibit only gradual differences. The polar cumarine $S 1$ is best solubilized by the tail-end type. The partially polar, bulky azodye $S 2$ is equally well solubilized by tail-end and mid-tail type. The weakly amphiphilic solubilizate $S 3$ is best solubilized by the mid-tail type. The head type is always inferior. Whether this is really inherent to the geometry, or only due to the presence of a long main chain spacer and to the imperfect polarity profile remains an open question. But the outcome is the same, as these limits are inherent to the chemical structure of head type polysoaps.

The changing preferences for tail-end and midtail types may be rationalized by an "excluded volume effect" of the polymer backbones in the respective positions. Polar, small solubilizates can be assumed to reside close to the "micellar surface," whereas solubilizates of amphiphilic structure should "insert" into the polymeric micelles. The first case is disfavored by a polymer backbone close to the head groups, the latter case by a backbone in the midst of the hydrophobic chains.

\section{Correlation of surface activity and solubilization capacity}

For the zwitterionic polysoap $P-5$ and its cationic analog $P-6$, solubilization capacities are nearly identical, neglecting specific interactions such as charge effects in the case of $S 4$ or $S 5$. However, surface activities are quite different: $P-5$ is moderately surface active, whereas the cationic $P-6$ hardly reduces the surface tension even at very high concentrations [33]. Reversely, the various zwitterionic analogs $P-1-P-5$ exhibit nearly identical moderate surface activities (Fig. 4), but their solubilization capacities differ substantially
(Table 2). Furthermore, within copolymer series Co-17 surface activity increases notably with surfactant monomer content, in contrast to copolymer series $\mathrm{Co}-13, \mathrm{Co}-14$, and $\mathrm{Co}-16$, whose surface activities do not depend on the copolymer composition [14]. But within all four copolymer series, the solubilization capacity per hydrophobic chain is approximately constant.

All these observations demonstrate that there is no primary correlation between surface activity and solubilization capacity in case of polysoaps. Any combination of the two properties exists, including the very interesting one combining high solubilization capacity with low surface activity (e.g., $P$-6). This result apparently contradicts theoretical considerations for low molecular weight surfactants, as high solubilization capacities should be favored by low interfacial tensions [7]. Possibly, in the case of polysoaps, the surface tension at the air-water interface and the interfacial tension between the aqueous phase and the solubilized material are not linked, due to the different aggregation equilibria present.

\section{Conclusions}

The solubilization capacity of polysoaps is a complex function of several variables. Generally, solubilization is improved by increasing the content of hydrophobic chains. Thus, main chain spacer groups should be minimized as much as possible. Further, solubilization is favored by appropriate choice of the polymer backbone, adjusting the polarity profile of the polysoap. Interactions of the solubilizates with the headgroups can substantially contribute to the solubilization capacity, in particular, when charged solubilizates are used and electrostatic interactions become important. However, in the case of uncharged dyes, electrostatic effects are of minor importance (if at all). Polymer geometry is an important factor, too, which has to be adapted to the structure of the solubilizate chosen. Tail-end type polysoaps are used preferentially for small and polar compounds, whereas weakly amphiphilic solubilizates are best solubilized by mid-tail polysoaps. Head-type polysoaps were less efficient. A general "ideal polysoap" structure for optimal solubilization does not exist, but the system to be chosen depends on the problem addressed. 
Worthnoting is that no correlation between solubilization capacity and solubilization sites, as judged from spectroscopic probing, was observed, nor was there any between solubilization capacity and surface activity.

\section{References}

1. Strauss UP (1989) In: Glass JE (ed) Polymers in Aqueous Media. Adv Chemistry Series 223, Am Chem Soc, Washington DC, pp 317-324

2. Bekturov EA, Bakauova ZKh (1986) In: Synthetic Water-Soluble Polymers in Solution. Hütig \& Wepf, Basel, pp 178-188

3. Anton P, Köberle P, Laschewsky A (1993) Makromol Chem 194:1-27

4. Solubilization is defined as "the preparation of thermodynamically stable isotropic solutions of substances normally insoluble or slightly soluble in a given solvent by the introduction of an additional amphiphilic component or components", according to ref. $6, \mathrm{pp} 68$

5. McBain MEL, Hutchinson E (1955) in: Solubilization and Related Phenomena. Academic Press, New York

6. Elworthy PH, Florence AT, MacFarlane CB (1968) in: Solubilization by Surface-Active Agents. Chapman and Hall, London

7. Oetter G, Hoffmann H (1988/89) J Disp Sci Techn 9:459-492

8. Strauss UP, Schlesinger MS (1978) J Phys Chem 82:1527-1532

9. Gao Z, Wasylishen RE, Kwak JCT (1989) Macromolecules 22:2544-2546

10. Binana-Limbelé W, Zana R (1990) Macromolecules 23:2731-2739

11. Chu DY, Thomas JK (1991) Macromolecules 24:2212-2216

12. Paleos CM, Margomenou-Leonidopoulou G, Malliaris A (1988) Mol Cryst Liq Cryst 161:385-394

13. Yang YJ, Engberts JFBN (1991) J Org Chem 56:4300-4304

14. Köberle P, Laschewsky A, van den Boogaard D (1992) Polymer 33:4029-4040

15. Seo T, Take S, Miwa K, Hamada K, Iijima T (1991) Macromolecules 24:4255-4263

16. Cochin D, Zana R, Candau F (1993) Polymer Int 30:491-498
17. Strauss UP, Jackson EG (1951) J Polym Sci 5:649-659

18. Jackson EG, Strauss UP (1951) J Polym Sci 5:473-484

19. Layton LH, Jackson EG, Strauss UP (1952) J Polym Sci 9:295-308

20. Strauss UP, Gershfeld NL (1954) J Phys Chem $58: 747-753$

21. Medalia AI, Freedman HH, Sinha S (1959) J Polym Sci 40:15-33

22. Ito K, Ono H, Yamashita Y (1964) J Coll Sci 19:28-39

23. Kiefer M (1990) Ph.D. thesis, Freiburg (Germany)

24. Boyer B, Durand S, Lamaty G, Moussamou-Missima JM, Pavia AA, Pucci B, Roque JP, Rouvière J (1991) J Chem Soc Perkin Trans 2:1311-1317

25. Arai K, Okabe T (1992) Polymer J 24:769-75

26. Anton P, Laschewsky A (1991) Makromol Chem Rapid Commun 12:189-196

27. Laschewsky A, Zerbe I (1991) Polymer 32:2070-2080

28. Anton P, Heinze J, Laschewsky A (1993) Langmuir 9:77-85

29. Anton P, Laschewsky A (1993) Makromol Chem 194:601-624

30. Tundo P, Kippenberger DJ, Politi MJ, Klahn P, Fendler JH (1982) J Am Chem Soc 104:5352-5358

31. Anton P (1993) Ph.D. thesis, Mainz (Germany)

32. Lunkenheimer K (1982) Tenside Deterg 19:272-281 and references therein

33. Laschewsky A, Zerbe I (1991) Polymer 32:2081-2086

34. Ringsdorf H, Schlarb B, Venzmer J (1988) Angew Chem Int Eng Ed 27:113-158

35. Finkelmann H, Rehage G (1984) Adv Polym Sci 60/61:163-171

36. Kalyanasundaram K, Thomas JK (1977) J Am Chem Soc 99:2039-2044

37. Dong DC, Winnik MA (1984) Can J Chem 62:2560-2566

38. Loew LM, Simpson L, Hassner A, Alexanion V (1979) J Am Chem Soc 101:5439-5440

39. Ephardt H, Fromherz P (1993) J Phys Chem $97: 4540-4547$

Received September 24, 1993; accepted November 25, 1993

Author's address:

Prof. André Laschewsky

Département de Chimie

Université Catholique de Louvain

Place L. Pasteur 1

B-1348 Louvain-la-Neuve, Belgium 